\title{
Inhibition of RXR and PPAR $\gamma$ ameliorates diet-induced obesity and type 2 diabetes
}

\author{
Toshimasa Yamauchi, ${ }^{1}$ Hironori Waki, ${ }^{1}$ Junji Kamon, ${ }^{1}$ Koji Murakami, ${ }^{2}$ \\ Kiyoto Motojima, ${ }^{3}$ Kajuro Komeda, ${ }^{4}$ Hiroshi Miki, ${ }^{1}$ Naoto Kubota, ${ }^{1}$ Yasuo Terauchi, ${ }^{1}$ \\ Atsuko Tsuchida, ${ }^{4}$ Nobuyo Tsuboyama-Kasaoka, ${ }^{5}$ Naoko Yamauchi, ${ }^{6}$ Tomohiro Ide, ${ }^{2}$ \\ Wataru Hori, ${ }^{2}$ Shigeaki Kato, ${ }^{7}$ Masashi Fukayama, ${ }^{6}$ Yasuo Akanuma, ${ }^{8}$ Osamu Ezaki, ${ }^{5}$ \\ Akiko Itai, ${ }^{9}$ Ryozo Nagai, ${ }^{1}$ Satoshi Kimura, ${ }^{1}$ Kazuyuki Tobe, ${ }^{1}$ Hiroyuki Kagechika, ${ }^{10}$ \\ Koichi Shudo, ${ }^{10}$ and Takashi Kadowaki ${ }^{1}$
}

\author{
${ }^{1}$ Department of Internal Medicine, Graduate School of Medicine, University of Tokyo, Tokyo, Japan \\ ${ }^{2}$ Central Research Laboratories, Kyorin Pharmaceutical, Tochigi, Japan \\ ${ }^{3}$ Department of Biochemistry, Meiji Pharmaceutical University, Tokyo, Japan \\ ${ }^{4}$ Division of Laboratory Animal Science, Animal Research Center, Tokyo Medical University, Tokyo, Japan \\ ${ }^{5}$ The Division of Clinical Nutrition, National Institute of Health and Nutrition, Tokyo, Japan \\ ${ }^{6}$ Department of Pathology, Graduate School of Medicine, and \\ ${ }^{7}$ Institute of Molecular and Cellular Biosciences, University of Tokyo, Tokyo, Japan \\ ${ }^{8}$ Institute for Diabetes Care and Research, Asahi Life Foundation, Tokyo, Japan \\ ${ }^{9}$ Institute of Medical Molecular Design, Tokyo, Japan \\ ${ }^{10}$ Graduate School of Pharmaceutical Sciences, University of Tokyo, Tokyo, Japan
}

Address correspondence to: Takashi Kadowaki, Department of Internal Medicine, Graduate School of Medicine, University of Tokyo, 7-3-1 Hongo, Bunkyo-ku, Tokyo 113-8655, Japan.

Phone: 81-3-5800-8818; Fax: 81-3-5689-7209; E-mail: kadowaki-3im@h.u-tokyo.ac.jp.

Hironori Waki and Junji Kamon contributed equally to this work.

Received for publication April 2, 2001, and accepted in revised form August 21, 2001.

\begin{abstract}
PPAR $\gamma$ is a ligand-activated transcription factor and functions as a heterodimer with a retinoid $\mathrm{X}$ receptor (RXR). Supraphysiological activation of PPAR $\gamma$ by thiazolidinediones can reduce insulin resistance and hyperglycemia in type 2 diabetes, but these drugs can also cause weight gain. Quite unexpectedly, a moderate reduction of PPAR $\gamma$ activity observed in heterozygous PPAR $\gamma$-deficient mice or the Pro12Ala polymorphism in human PPAR $\gamma$, has been shown to prevent insulin resistance and obesity induced by a high-fat diet. In this study, we investigated whether functional antagonism toward PPAR $\gamma /$ RXR could be used to treat obesity and type 2 diabetes. We show herein that an RXR antagonist and a PPAR $\gamma$ antagonist decrease triglyceride (TG) content in white adipose tissue, skeletal muscle, and liver. These inhibitors potentiated leptin's effects and increased fatty acid combustion and energy dissipation, thereby ameliorating HF diet-induced obesity and insulin resistance. Paradoxically, treatment of heterozygous PPAR $\gamma$-deficient mice with an RXR antagonist or a PPAR $\gamma$ antagonist depletes white adipose tissue and markedly decreases leptin levels and energy dissipation, which increases TG content in skeletal muscle and the liver, thereby leading to the re-emergence of insulin resistance. Our data suggested that appropriate functional antagonism of PPAR $\gamma / \mathrm{RXR}$ may be a logical approach to protection against obesity and related diseases such as type 2 diabetes.
\end{abstract}

J. Clin. Invest. 108:1001-1013 (2001). DOI:10.1172/JCI200112864.

\section{Introduction}

PPAR $\gamma$ is a ligand-activated transcription factor and a member of the nuclear hormone receptor superfamily that functions as a heterodimer with a retinoid $\mathrm{X}$ receptor (RXR) (1-5). Agonist-induced activation of PPAR $\gamma / \mathrm{RXR}$ is known to increase insulin sensitivity (6, 7), and thiazolidinediones (TZD), which have the ability to directly bind and activate PPAR $\gamma(6)$ and stimulate adipocyte differentiation $(2,3,8)$, are used clinically to reduce insulin resistance and hyperglycemia in type 2 diabetes, though these drugs have been associated with weight gain (9). UK Prospective Diabetes Study has clearly demonstrated that weight gain associated with diabetes treatment partially cancels the beneficial effects of tight blood glucose control on cardiovascular events and mortality (10). Thus, we sought to identify novel therapeutic strategies not only for insulin resistance but also obesity.

We and others have reported that heterozygous PPAR $\gamma$-deficient mice are protected from high-fat diet-induced (HF diet-induced) or aging-induced adipocyte hypertrophy, obesity, and insulin resistance $(11,12)$. Consistent with this, the Pro12Ala polymorphism in human PPAR $\gamma 2$, which moderately reduces the transcriptional activity of PPAR $\gamma$, has been shown to confer resistance to type 2 diabetes (13-15). These 
findings raise the following important unresolved issues. First, it remains to be ascertained whether functional antagonism of PPAR $\gamma / \mathrm{RXR}$, e.g., administering an RXR antagonist or a PPAR $\gamma$ antagonist, could indeed serve as an effective treatment strategy for obesity and type 2 diabetes. Second, the mechanism by which reduced PPAR $\gamma /$ RXR activity improves insulin resistance is unclear. Third, whether further reduction of PPAR $\gamma / R X R$ activity is associated with further improvement of insulin resistance, remains to be clarified. To address these issues, we employed pharmacological inhibitors of PPAR $\gamma / \mathrm{RXR}$, a PPAR $\gamma$ antagonist, and an RXR antagonist, in both wild-type and heterozygous PPAR $\gamma$-deficient mice.

Bisphenol A diglycidyl ether (BADGE) has been reported to act as a relatively selective antagonist for $\operatorname{PPAR} \gamma(16)$. In fact, the inhibition of PPAR $\gamma$ transcriptional activity by BADGE was approximately $70 \%$, whereas PPAR $\delta$ was inhibited by approximately $23 \%$ and PPAR $\alpha$ was not inhibited. In addition, BADGE was ineffective in attenuating glucocorticoid receptormediated transcriptional activation; however, an inhibitory effect of BADGE $(\sim 30 \%)$ on ligand-induced activation of RXR $\alpha$ was observed. We have recently identified a synthetic RXR antagonist, HX531 (17), and herein show HX531 to be a potential PPAR $\gamma /$ RXR inhibitor in an in vitro transactivation assay and to prevent triglyceride (TG) accumulation in 3T3L1 adipocytes. We also show that administration of the RXR antagonist HX531 or the PPAR $\gamma$ antagonist BADGE to mice on a HF diet decreases TG content in white adipose tissue (WAT), skeletal muscle, and the liver due to increased leptin effects and increased fatty acid combustion and energy dissipation, thereby ameliorating HF diet-induced obesity and insulin resistance, in proportion to their potencies as PPAR $\gamma / \mathrm{RXR}$ inhibitors in vitro. Paradoxically, treatment of heterozygous PPAR $\gamma$-deficient mice with the RXR antagonist or the PPAR $\gamma$ antagonist depletes WAT and markedly decreases leptin levels and energy dissipation, which increases the TG content of skeletal muscle and the liver, thereby causing re-emergence of insulin resistance. Our data suggest that appropriate functional antagonism of PPAR $\gamma / \mathrm{RXR}$ may be a logical approach to protection against obesity and related diseases such as type 2 diabetes.

\section{Methods}

Chemicals. HX531 (17), rosiglitazone, LG100268 (7), and BADGE (16) were synthesized as described elsewhere. We measured the plasma concentrations of HX531 and BADGE by HPLC (HX531) (17) and gas chromatography (BADGE) (16) in C57 mice orally administered 100 $\mathrm{mg} / \mathrm{kg}$ of HX531 or $3 \mathrm{~g} / \mathrm{kg}$ of BADGE. The maximal concentration $\left(C_{\max }\right)$, the time required until maximal concentration $\left(T_{\max }\right)$, the area under the plasma concentration time curve (AUC), and the elimination halflife $\left(t_{1 / 2}\right)$ for HX531 were $4.1 \mu \mathrm{g} / \mathrm{ml}, 1.5$ hours, $19.3 \mu \mathrm{g}$ $\mathrm{h} / \mathrm{ml}$, and 1.9 hours, respectively. The $C_{\max }, T_{\max }$, AUC, and $t_{1 / 2}$ for BADGE were $0.45 \mu \mathrm{g} / \mathrm{ml}, 9$ hours, $8.2 \mu \mathrm{g}$ $\mathrm{h} / \mathrm{ml}$, and 6.4 hours, respectively. Thus, it is reasonable to assume that PPAR $\gamma$ and RXR in animal tissues are exposed to concentrations of compounds essentially comparable to those in in vitro cell culture experiments. Wy-14,643 was purchased from Biomol Research Laboratories (Plymouth Meeting, Pennsylvania, USA). T3, 3-isobutyl-1-methylxanthine, and insulin were from Sigma Chemical Co. (St. Louis, Missouri, USA) $1 \alpha$, 25-dihydroxy-vitamin D3 was from Calbiochem-Novabiochem Corp. (San Diego, California, USA) Dexamethasone was purchased from Wako Pure Chemical Industries Ltd. (Osaka, Japan). All other materials were from the sources given in refs. 8, 11, 17, and 18.

Animals, in vivo glucose homeostasis, assay of endogenous serum leptin concentrations, leptin sensitivity, and $\mathrm{O}_{2}$ consumption. Heterozygous PPAR $\gamma$-deficient mice have been described previously (11). All other animals were purchased from Nippon CREA Co. Ltd. (Shizuoka, Japan) Six-week-old mice were fed powdered chow according to methods described previously (11). HX531, BADGE, LG100268, or Wy-14,643 was given as a $0.1 \%, 3 \%, 0.02 \%$, or $0.01 \%$ food admixture, respectively, or an indicated percentage $(8,11)$, and no toxicity, such as liver damage, was observed. Insulin tolerance tests were carried out according to a method described previously (11), with slight modification. Leptin was assayed with the ELISA-based Quantikine M mouse leptin immunoassay kit (R\&D Systems Inc., Minneapolis, Minnesota, USA) according to the manufacturer's instructions. For leptin sensitivity (11), leptin Sigma Chemical Co., St. Louis, Missouri, USA) was administered to mice after treatment with HX531 for 10 days as a daily intraperitoneal injection of $10 \mu \mathrm{g} / \mathrm{g}$ body weight/day. Isotonic sodium chloride solution was administered to the controls. Food intake and body weight were measured to assess the effects of leptin administration. Oxygen consumption was determined as described previously (18). The animal care and procedures were approved by the Animal Care Committee of the University of Tokyo.

Insulin resistance index. The insulin resistance index was calculated from the product of the area of glucose and insulin multiplied by $10^{-2}$ as described in ref. 7 . The areas of glucose and insulin curves were calculated by multiplying the cumulative mean height of the glucose values $\left(1 \mathrm{mg} \mathrm{ml}^{-1}=1 \mathrm{~cm}\right)$ and insulin values $\left(1 \mathrm{ng} \mathrm{ml}^{-1}=1 \mathrm{~cm}\right)$, respectively, by time $(60 \mathrm{~min}=1 \mathrm{~cm})$. The results are expressed as the percentage of the value of each control.

Histological analysis of adipose and hepatic tissues and determination of adipocyte size. Adipose tissue was removed from each animal and fixed in 10\% formaldehyde/PBS and maintained at $4^{\circ} \mathrm{C}$ until use. Fixed specimens were dehydrated, embedded in tissue-freezing medium (Tissue-Tek OCT compound; Miles Inc., Elkhart, Indiana, USA) and frozen in dry ice and acetone. WAT was cut into $10-\mu \mathrm{m}$ sections, and the sections were mounted on silanized slides. The adipose tissue was stained with hematoxylin and eosin (H\&E). Mature white adipocytes 
a

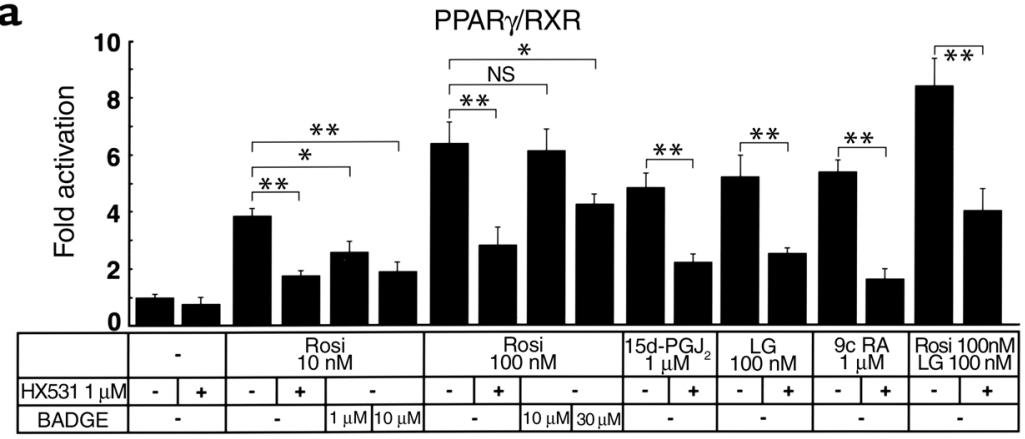

c

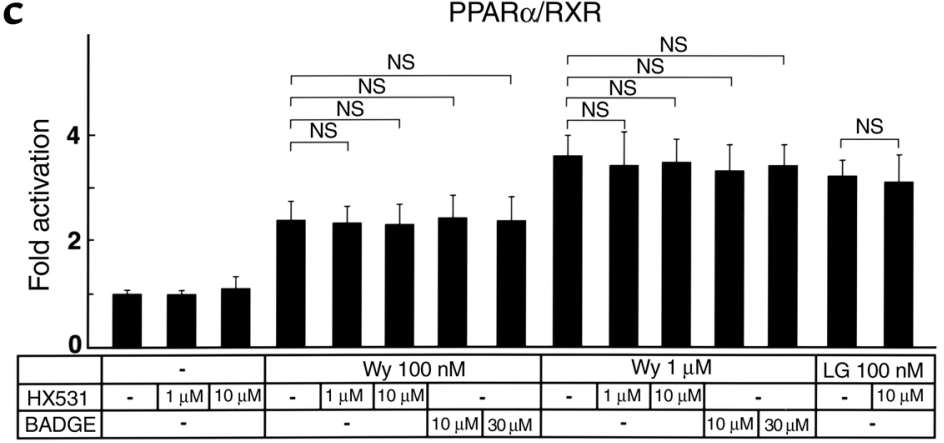

b
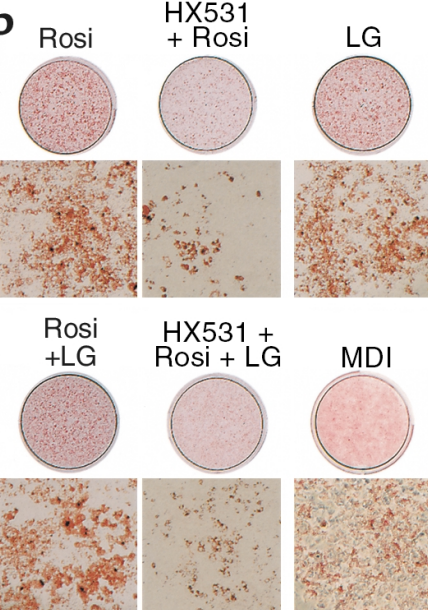

HX531

$+\mathrm{LG}$

,

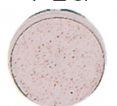

16.2.
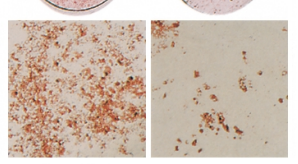

MDI

HX531

$+\mathrm{MDI}$

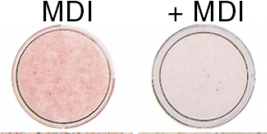

d

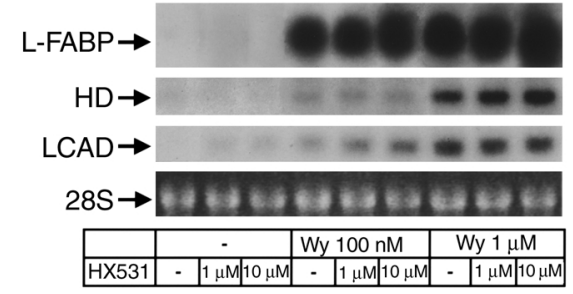

Figure 1

The RXR antagonist HX531 serves as a functional PPAR $\gamma / R X R$ inhibitor (a and $\mathbf{c})$. Transactivation analysis of PPAR $\gamma / R X R(\mathbf{a})$, PPAR $\alpha / R X R(\mathbf{c})$. CV-1 cells were cotransfected with RXR $\alpha$ with an expression vector for PPAR $\gamma$ or PPAR $\alpha$. PPAR $\gamma / R X R$ or PPAR $\alpha / R X R$ activity was assessed on a PPRE-tk LUC (24) as described previously $(22,23)$. CV-1 cells were treated with the indicated concentrations of rosiglitazone (Rosi), LG100268 (LG), 15-deoxy- $\Delta^{12,14}$ prostaglandin $\mathrm{J}_{2}$ (15d-PG $\mathrm{J}_{2}$ ), Wy-14,643 (Wy), BADGE, and HX531. 9-cis-retinoic acid (b) 3T3L1 adipocyte differentiation assay. Oil red $\mathrm{O}$ staining for fat accumulation in cells at day 6 after induction. Cells were grown to confluence and then induced to differentiate

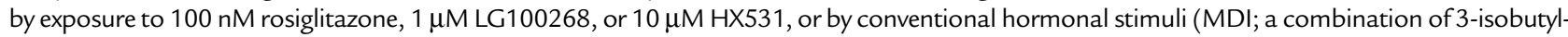
1-methylxanthine, dexamethasone, and insulin). (d) Amounts of the mRNAs of liver-type fatty acid-binding protein (L-FABP), HD, and long-chain acyl-CoA dehydrogenase (LCAD) in rat hepatoma FAO cells treated with the indicated concentrations of Wy-14,643 and HX531 for 24 hours. Each bar represents the mean $\pm \mathrm{SE}(n=5-10) .{ }^{*} P<0.05,{ }^{*} P<0.01$ with versus without HX531 or BADGE. NS, no significant difference.

were identified by their characteristic multilocular appearance. Total adipocyte areas were traced manually and analyzed with Win ROOF software (Mitani Co. Ltd., Chiba, Japan). White adipocyte areas were measured in 400 or more cells per mouse in each group according to methods previously described $(8,11)$.

$R N A$ preparation, Northern blot analysis, RNase protection assay, phosphatidylinositol 3-kinase assay, immunoprecipitation, and immunoblotting. Total RNA was prepared from cells or tissues with TRIzol (Invitrogen Corp., Carlsbad, California, USA), according to the manufacturer's instructions. Total RNA from 5-10 mice in each group was pooled, and aliquots were subjected to Northern blot analysis with the probes for rat acyl-CoA oxidase (ACO) (a gift of T. Hashimoto), mouse CD36, uncoupling protein 2 (UCP2), PPAR $\alpha$, or resistin $\mathrm{CDNA}$, or RNase protection assay was performed, using a standard protocol, to measure mRNAs of TNF- $\alpha(8,11,19)$. The radioactivity in each band was quantified, and the fold change in each mRNA was calculated after correction for loading differences by measuring the amount of $28 \mathrm{~S}$ rRNA. Very low levels (< $10 \%)$ of aP2 mRNA were detected in muscle as compared with those in WAT (20).
In contrast, at least comparable levels of CD36, SREBP1, SCD1, ACO, and UCP2 mRNAs were detected in muscle compared with those in WAT. These data suggest that the results of muscle tissue essentially represent those of muscle cells, despite the muscle being contaminated with a small amount $(<10 \%)$ of intermyocyte fat. The procedures used for phosphatidylinositol 3-kinase (PI 3-kinase) assay, immunoprecipitation, and immunoblotting were described previously (21). Representative data from one of three independent experiments are shown.

Cell culture, transfection, transactivation assays, and induction of adipocyte differentiation. CV-1 and 3T3L1 cells were cultured in DMEM with 10\% FCS, and transfection and induction of adipogenic differentiation were carried out according to methods described previously $(11,22,23)$. Heterodimers were formed by cotransfecting RXR $\alpha$ with an expression vector for PPAR $\gamma$, PPAR $\alpha$, PPAR $\delta, T R, R A R$, or VDR. PPAR $\gamma / R X R$, or PPAR $\alpha / R X R$, or PPAR $\delta / R X R$ activity was assessed on a ACO PPRE-tk LUC (24), and RXR/TR, RXR/RAR, or RXR/VDR activity was tested respectively on DR-4, 5-tk LUC, and DR-3-tk-CAT, as described previously $(22,23)$. 


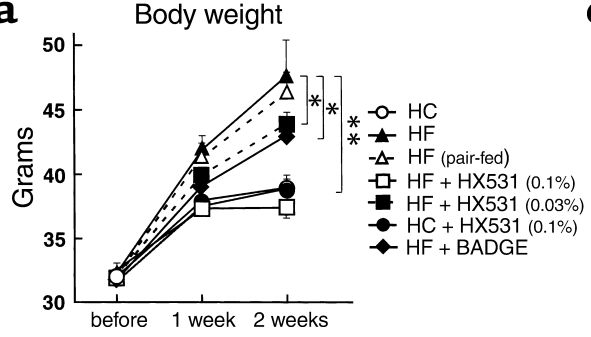

C

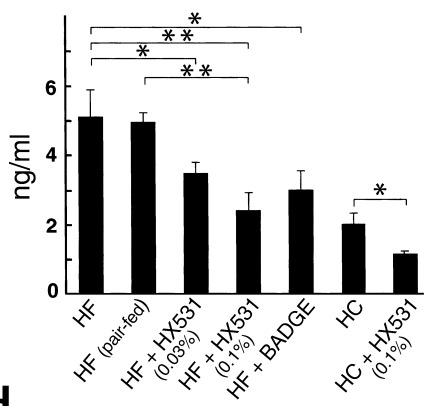

b

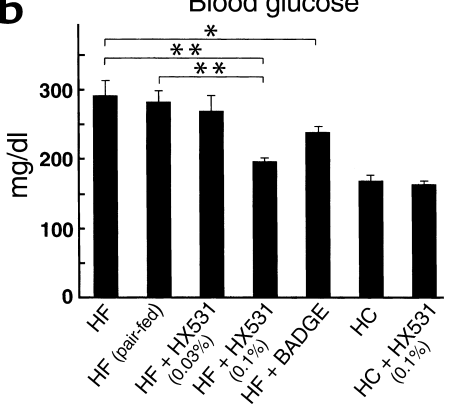

d

Insulin tolerance test

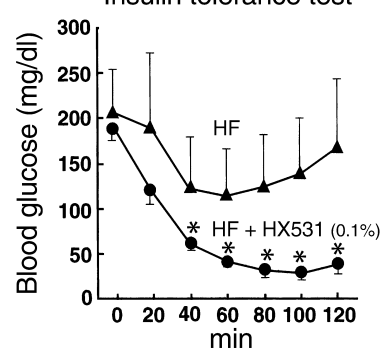

Figure 2

Both the RXR antagonist HX531 and the PPAR $\gamma$ antagonist BADGE exert antiobesity and antidiabetic effects in proportion to their potencies as PPAR $\gamma / R X R$ inhibitors in vitro (a-d). Body weight (a), fasting blood glucose (b), fasting plasma insulin (c), and insulin tolerance test (d) of KKAy mice untreated or treated with HX531 (+HX531) or BADGE (+BADGE) for 2 weeks while on the HF diet or the HC diet. HX531 or BADGE was given as an indicated percentage of food admixture. The same amounts of food were given to the pair-fed group as to mice treated with HX531, given as a $0.1 \%$ food admixture. Each bar represents the mean $\pm \mathrm{SE}(n=5-10) .{ }^{*} P<0.05,{ }^{*} P<0.01$ with versus without $\mathrm{HX} 531$ or BADGE.
Leptin treatment. Leptin treatment was performed as described previously (25). An Alzet micro-osmotic pump (model 1002, Alza Corp., Palo Alto, California, USA) was inserted subcutaneously into the back of each mouse. The pumps delivered 0 or 5 (low doses) or $50 \mu \mathrm{g}$ (high dose) of mouse recombinant leptin (Sigma Chemical Co.) per day for 12 days in a total volume of $0.1 \mathrm{ml}$ PBS.

Lipid metabolism. Liver and muscle homogenates were extracted, and their TG and fatty acyl-CoA (FA-CoA) content were determined as described previously (22, 26), with some modifications.

\section{Results}

HX531 serves as a PPAR $\gamma / R X R$ inbibitor. Because PPAR $\gamma$ functions as a heterodimer with $\operatorname{RXR}(1,3,5)$, we used a cotransfection reporter assay to screen compounds for responsiveness via the peroxisome proliferator response element (PPRE) and identified HX531 (17) as a PPAR $\gamma /$ RXR inhibitor (Figure 1a). In the presence of PPAR $\gamma$ agonists such as rosiglitazone (6) or 15-deoxy$\Delta^{12,14}$ prostaglandin $\mathrm{J}_{2}(27,28)$, RXR agonists such as LG100268 (7), or 9-cis retinoic acid $(29,30)$, or both, HX531 functioned as a partial inhibitor and produced a concentration-dependent decrease in transactivation by way of PPRE (24) (Figure 1a). We next analyzed the effects of HX531 on 3T3L1 adipocyte differentiation and found HX531 to be capable of inhibiting adipocyte differentiation in 3T3L1 cells induced by rosiglitazone, LG100268, or both, as well as by conventional hormonal stimuli (a combination of insulin, dexamethasone, and 3-isobutyl-1-methylxanthine) (Figure 1b).

By contrast, HX531 had no apparent effect on PPAR $\alpha / R X R(1,4)$ agonist-induced transactivation (Figure 1c) or on the expression of molecules induced by the PPAR $\alpha$ agonist $(18,19,22,31,32) \mathrm{Wy}-14,643$ in

Table 1

Effects of HX531 on other RXR partners in vitro and in vivo

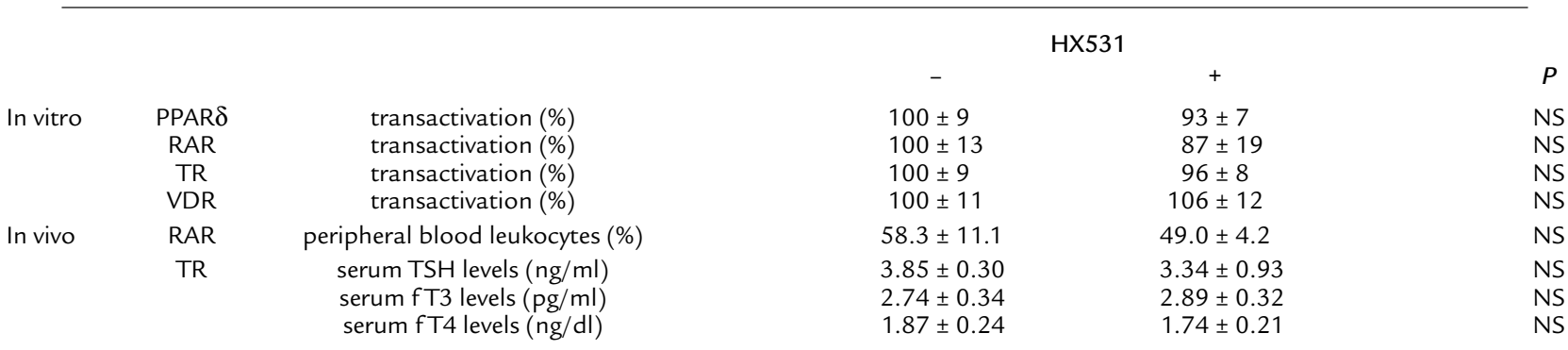

Transactivation analysis of PPAR $\delta / R X R, R A R / R X R, T R / R X R$, and VDR/RXR in vitro. CV-1 cells were treated with $100 \mathrm{nM}$ of carbaprostacyclin, T3, all trans retinoic acid (atRA), or $1 \alpha, 25$-dihydroxy-vitamin D3 (VD3) with or without $1 \mu \mathrm{M}$ of HX531. The results are expressed as the percentage of the value of control cells without HX531. The percentages of peripheral blood leukocytes and serum TSH, free T3, and free T4 levels of KKAy mice untreated or treated with HX531 for 4 weeks while on the HF diet are shown. HX531 was given as a $0.1 \%$ food admixture. Values are mean \pm SE $(n=5-10)$. NS, no significant difference, with versus without HX531. 
Figure 3

Both the RXR antagonist HX531 and the PPAR $\gamma$ antagonist BADGE exert antiobesity and antidiabetic effects in part through leptindependent pathways (a and $\mathbf{b}$ ). Rectal temperature (a) and oxygen consumption (b) of KKAy mice untreated or treated with HX531 (+HX531) for 2 weeks while on the HF diet or the HC diet. Serum leptin levels of C57 (c) or KKAy mice (d) untreated or treated with HX531, BADGE (+BADGE), or LG100268 (+LG) for 2 weeks while on the HF diet. The left sides of the arrows are before-treatment (c) and after 1-week treatment (d) levels. (e) Leptin protein levels in the

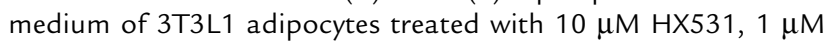
LG100268, or $100 \mathrm{nM}$ rosiglitazone (Rosi) for 24 hours. (f) Effects of intraperitoneal leptin administration in untreated C57 mice or C57 mice treated with HX531 for 10 days while on the HF diet. Groups of untreated mice or mice treated with HX531 received an intraperitoneal injection of either leptin $(10 \mu \mathrm{g} / \mathrm{g} / \mathrm{d})(+)$ or isotonic sodium chloride solution (-). Food intake/12 h (left) and weight changes $/ 12 \mathrm{~h}$ (right) were measured. ( $\mathbf{g}$ and $\mathbf{h}$ ) WAT weight $(\mathbf{g})$ and insulin resistance index (7) (h) of C57 and $d b / d b$ mice untreated or treated with HX531 or BADGE for 2 weeks while on the HF diet. The results are expressed as the percentage of the value of untreated mice on the HF diet $(\mathbf{g}$ and $\mathbf{h})$. Each bar represents the mean $\pm \mathrm{SE}$ $(n=5-10) .{ }^{*} P<0.05,{ }^{*} P<0.01, C 57$ versus $d b / d b$ or untreated versus treated with HX531, BADGE, Rosi, LG, or leptin.

the hepatoma cell line Fao (Figure 1d and data not shown). It also had minimal effects on other RXR partners (33), e.g., PPAR $\delta$, thyroid hormone receptor (TR), retinoic acid receptor (RAR), and vitamin $\mathrm{D}$ receptor (VDR) in vitro and in vivo, including serum thyroidstimulating hormone (TSH), free T3, and free T4 levels, the number of peripheral blood leukocytes, bone marrow blasts, osteoclasts, or osteoblasts, or the amount of osteoid in vivo (Table 1 and data not shown). These findings suggest that HX531 serves as a PPAR $\gamma / \mathrm{RXR}$ inhibitor. As reported previously (16), BADGE acted as a relatively selective antagonist for PPAR $\gamma$ (Figure 1a), but did not inhibit PPAR $\alpha$ (Figure 1c). However, a 100fold higher dose of BADGE was required to show a similar potency of antagonistic activity in the transactivation assay specific to PPAR $\gamma /$ RXR (Figure 1a).

Both the RXR antagonist HX531 and the PPAR yantagonist $B A D G E$ exert antiobesity and antidiabetic effects in proportion to their potencies as PPAR $\gamma / R X R$ inhibitors in vitro. We investigated the effects of the RXR antagonist HX531 and the PPAR $\gamma$ antagonist BADGE on body weight, glucose, and insulin concentrations in KKAy mice (34) on both a HF and a high-carbohydrate (HC) diet. Untreated KKAy mice on the HF diet gained significantly more weight than the mice on the HC diet (Figure $2 a)$. In contrast, treatment with HX531 or BADGE prevented a time-dependent increase in weight on the HF diet (Figure 2a). Treatment with the RXR antagonist or the PPAR $\gamma$ antagonist also prevented HF diet-induced hyperglycemia (Figure $2 \mathrm{~b}$ ) and hyperinsulinemia (Figure 2c). On the HF diet, the glucose-lowering effect of insulin was greater in mice treated with HX531 than in untreated mice (Figure 2d). These findings indicate that the RXR antagonist and the PPAR $\gamma$ antagonist have potential as antiobesity and antidia- a

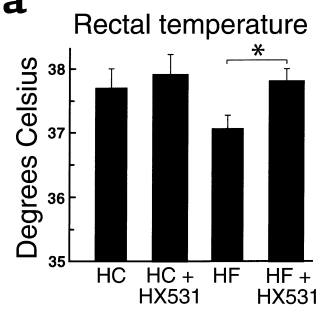

b

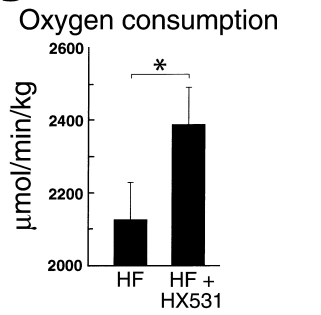

c

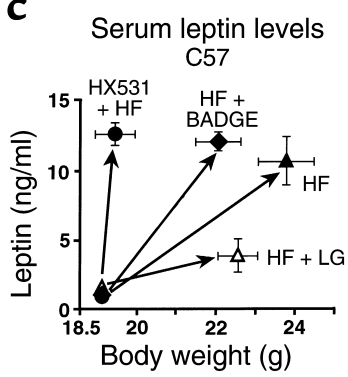

d

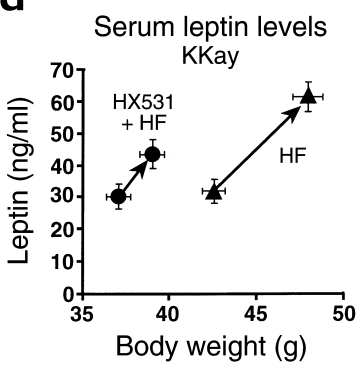

f Leptin sensitivity
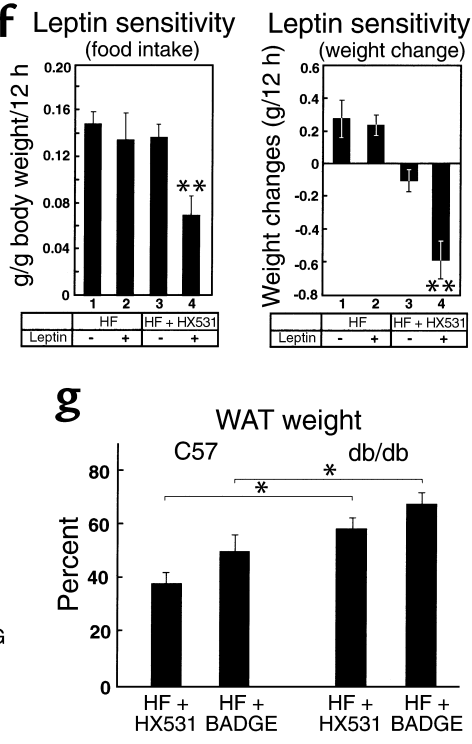

h

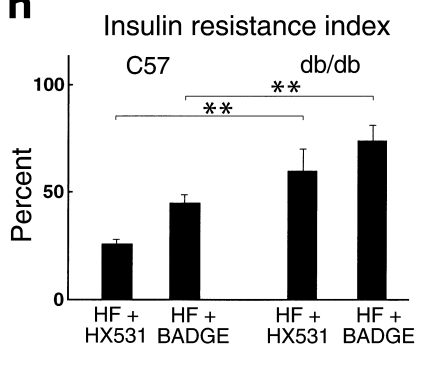

betic drugs. Moreover, the potencies of HX531 and BADGE as antiobesity and antidiabetic drugs (Figure 2 , a-c) appeared to be essentially proportional to their potencies as PPAR $\gamma /$ RXR inhibitors in vitro (Figure 1a).

Both the RXR antagonist HX531 and the PPAR $\gamma$ antagonist $B A D G E$ exert antiobesity and antidiabetic effects in part through leptin-dependent pathways. Food intake was slightly, though not significantly, lower in mice treated with the RXR antagonist HX531 and the PPAR $\gamma$ antagonist BADGE on the HF diet (Figure 3f, left, lanes 1 and 3 and data not shown). The observations that mice treated with HX531 were protected from HF diet-induced obesity (Figure 2a) and insulin resistance (Figure 2, b and c), even when compared with pair-fed controls, may indicate that HX531 increased energy expenditure. Indeed, rectal temperature was significantly higher (Figure 3a) and oxygen consumption was significantly increased in mice treated with HX531 (Figure 3b). We next investigated whether leptin (35) might account for these phenotypes in mice treated 
a

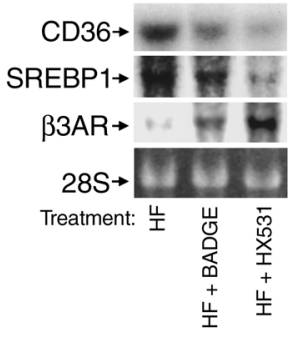

b

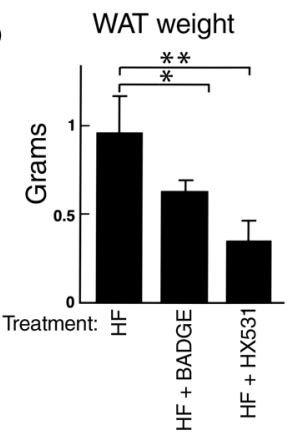

d

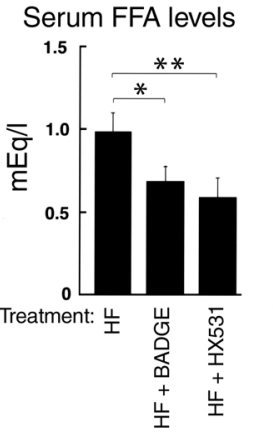

e

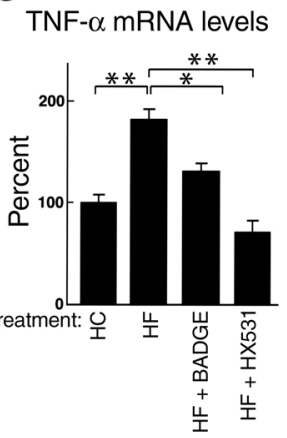

C
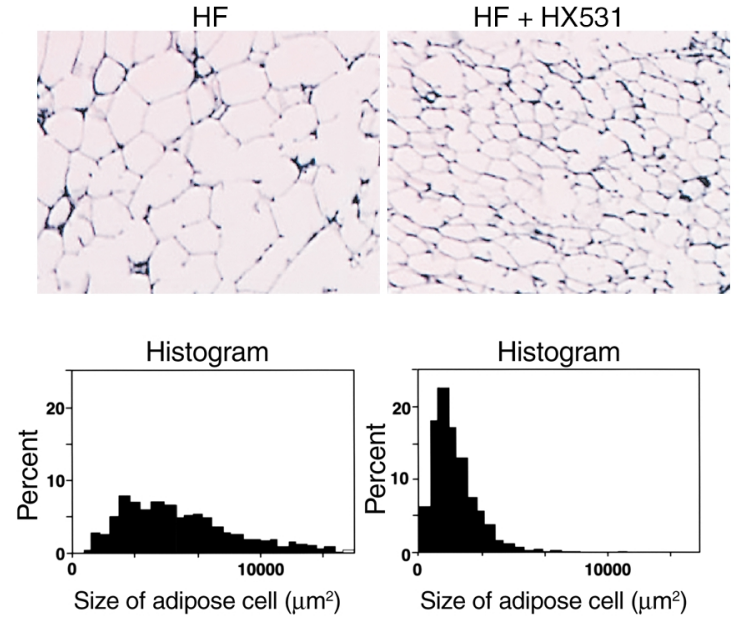

Figure 4

Both the RXR antagonist HX531 and the PPAR $\gamma$ antagonist BADGE reduce expressions of the molecules involved in fatty acid influx and lipogenesis and increase expression of $\beta 3$-AR in WAT. (a) Amounts of the mRNAs of FAT/CD36, SREBP1, and $\beta 3$-AR in WAT (a) of KKAy mice. (b and $\mathbf{c}$ ) WAT mass (b), histological analysis (top), and cell size distribution (bottom) (c) of epididymal WAT from KKAy mice. (d-f) Serum FFA levels (d), TNF- $\alpha$ mRNA levels (e), and resistin mRNA levels in WAT (f) of KKAy mice, untreated (HF), treated with HX531 (HF + HX531), or with BADGE (HF + BADGE) for 2 weeks while on the HF diet. HX531 or BADGE was given as a $0.1 \%$ or $3 \%$ food admixture, respectively. Each bar represents the mean $\pm \mathrm{SE}(n=5-10) .{ }^{*} P<0.05,{ }^{*} P<0.01, \mathrm{HF}$ versus HF + HX531 or HF + BADGE.

with the PPAR $\gamma /$ RXR inhibitor. The serum leptin levels normalized by body weight in both normal wild-type (C57) and KKAy mice treated with the RXR antagonist HX531 or the PPAR $\gamma$ antagonist BADGE were higher than those of untreated mice (Figure 3, $c$ and d). Expression and secretion of leptin into the medium by HX531treated 3T3L1 adipocytes were also significantly higher than those by untreated cells in vitro (Figure $3 e$ and data not shown), suggesting that the increase in serum leptin levels may be due to HX531-induced derepression of leptin gene transcription by PPAR $\gamma / \operatorname{RXR}(36)$.

Moreover, leptin sensitivity as assessed by reductions in food intake and body weight in response to exogenously administered leptin was significantly increased in wild-type mice treated with HX531 (Figure 3f), even when compared with pair-fed controls (data not shown), raising the possibility that increased leptin effects may contribute to the effects of PPAR $\gamma /$ RXR inhibitors. In wild-type mice, HX531 or BADGE largely prevented HF diet-induced obesity and insulin resistance (Figure $3, \mathrm{~g}$ and $\mathrm{h}$, left). In contrast, the antiobesity and antidiabetic effects of the RXR antagonist or the PPAR $\gamma$ antagonist were partially attenuated in $d b / d b$ mice (35), which are leptin receptor deficient (Figure 3, $\mathrm{g}$ and $\mathrm{h}$, right). These findings suggest that the RXR antagonist and the PPAR $\gamma$ antagonist exerted their antiobesity and antidiabetic effects through both leptin-dependent and independent pathways.
Both the RXR antagonist HX531 and the PPAR rantagonist $B A D G E$ decrease molecules involved in fatty acid influx into WAT by direct antagonism of PPAR $\gamma / R X R$ and concomitantly decrease lipogenic enzymes and increase $\beta 3-A R$ via leptin effects. In WAT, where PPAR $\gamma$ is expressed most predominantly, treatment with the RXR antagonist HX531 or the PPAR $\gamma$ antagonist BADGE reduced the expression of fatty acid translocase/CD36 (FAT/CD36) (ref. 37; Figure 4a), the promoter of which contains PPRE, indicating that HX531 and BADGE did indeed function as inhibitors of PPAR $\gamma / \mathrm{RXR}$ in vivo. In WAT from mice treated with HX531 or BADGE, reduced expressions of lipogenic enzymes such as sterol regulatory element-binding protein 1 (SREBP1) (Figure $4 a$ ), stearoyl-CoA desaturase 1 (SCD1) (data not shown), and increased expression of $\beta 3$-adrenergic receptor ( $\beta 3$-AR) (Figure 4a) were also observed in proportion to their increased leptin effects (Figure $3 \mathrm{c}$ and see Figure 7c) (38) and decreased PPAR $\gamma /$ RXR effects (Figure 1b) (39). These alterations of gene expression may in concert prevent adipocyte hypertrophy (Figure 4c) and reduce WAT mass (Figure 4b), and thereby obesity, on the HF diet. These data suggest that the RXR antagonist and the PPAR $\gamma$ antagonist prevented adipocyte hypertrophy, which ultimately alleviated insulin resistance via diminution of free fatty acids (FFA) (Figure 4d), TNF- $\alpha$ (Figure 4e) (40) and resistin (Figure 4f) (41), at least in part. 
Both HX531 and BADGE decrease molecules involved in fatty acid influx into muscle by direct antagonism of $P P A R \gamma / R X R$, and decrease lipogenic enzymes and increase fatty acid combustion and energy dissipation. In skeletal muscle in which PPAR $\gamma$ was relatively abundantly expressed, the RXR antagonist HX531 or the PPAR $\gamma$ antagonist BADGE also reduced expression of FAT/CD36 (Figure 5a). In addition, HX531 or BADGE decreased expressions of lipogenic enzymes such as SREBP1 (data not shown) and SCD1 (Figure 5a) and increased expressions of molecules involved in fatty acid combustion such as ACO, and energy dissipation, such as UCP2 (Figure 5a), in proportion to their increased leptin effects (Figure $3 c$ and see Figure 7c) $(38,42)$ and decreased PPAR $\gamma /$ RXR effects (Figure $1 \mathrm{~b}$ ). These alterations of gene expression by HX531 or BADGE appeared to reduce long-chain FA-CoA (Figure 5b) and TG content in muscle (Figure 5c), thereby improving insulin signal transduction (43), as demonstrated by increases in insulin-induced tyrosine phosphorylation of the insulin receptor (IR), insulin receptor substrate 1 (IRS-1) and IRS-2, and insulin-stimulated PI 3-kinase activity in phosphotyrosine (PY), and IRS-1 and IRS-2 immunoprecipitates of skeletal muscle (Figure $5 \mathrm{~d}$ ).

Both the RXR antagonist HX531 and the PPAR $\gamma$ antagonist $B A D G E$ increase molecules involved in fatty acid combustion and energy dissipation via leptin and PPAR $\alpha$ pathways in the liver and brown adipose tissue. In contrast, expression of FAT/CD36 was markedly increased in the livers of mice treated with the RXR antagonist HX531 or the PPAR $\gamma$ antagonist BADGE (Figure 6, a and b), where PPAR $\alpha$ was predominantly expressed. Moreover, expression of enzymes involved in $\beta$-oxidation, such as peroxisomal enoyl-CoA hydratase/3-hydroxyacyl-CoA dehydrogenase (HD), ACO, and UCP2 were markedly increased in mice treated with HX531 or BADGE (Figure 6 , a and b). These data strongly suggest PPAR $\alpha$ pathways to be activated in the liver treated with the RXR antagonist or the PPAR $\gamma$ antagonist, since these effects were recapitulated by Wy-14,643, a PPAR $\alpha$ agonist (Figure 6a) $(18,19$, $22,31)$. This HX531- or BADGE-induced activation of PPAR $\alpha$ pathways presumably occurred via moderate functional antagonism of PPAR $\gamma / \mathrm{RXR}$, since PPAR $\gamma$ heterozygous deficiency also activated PPAR $\alpha$ pathways (see Figure 8a, lane 4). Activation of PPAR $\alpha$ pathways by HX531 or BADGE was partially abrogated in $d b / d b$ mice (Figure 6a), suggesting that the RXR antagonist and the PPAR $\gamma$ antagonist exerted these effects, in part, through leptin signaling pathways $(1,42)$. Moreover, expressions of lipogenic enzymes such as SREBP1 (Figure 6b) and SCD1 (data not shown) were markedly reduced, possibly as a consequence of increased leptin levels (Figure $3 c$ and Figure $7 \mathrm{c})(38,42)$.

Marked elevations of enzymes involved in $\beta$-oxidation and UCP2, as well as this reduction of lipogenic enzymes (Figure 6, $a$ and $b$ ), appeared to significantly reduce liver weight (data not shown) and FA-CoA content (Figure 6c) and to ameliorate severe fatty liver (Figure $6 \mathrm{~d})(25,34)$ in wild-type mice treated with HX531 or BADGE while on the HF diet. The reduction of FA-CoA and amelioration of fatty liver by HX531 were associated with increased expression of glucokinase (GK), decreased expression of enzymes involved in gluconeogenesis, such as phosphoenolpyruvate carboxykinase (PEPCK) and glucose-6-
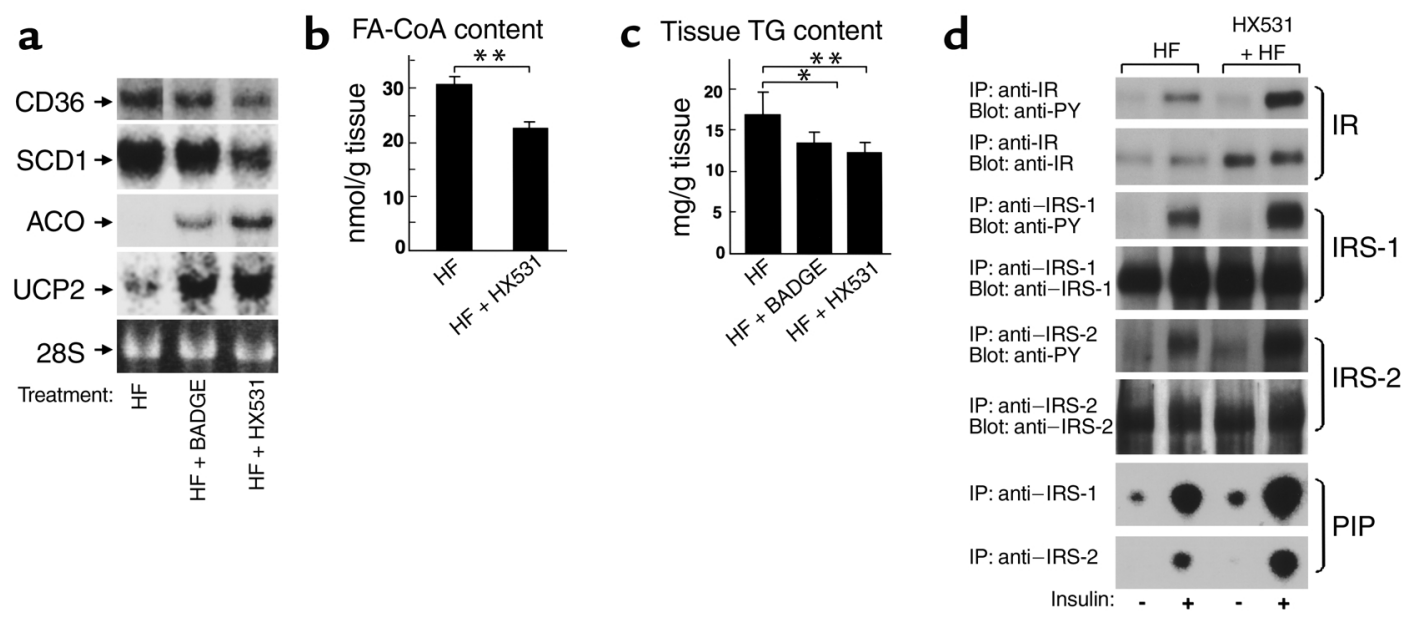

\section{Figure 5}

The RXR antagonist HX531 and the PPAR $\gamma$ antagonist BADGE both decrease molecules involved in fatty acid influx and lipogenesis and increase molecules involved in energy consumption in skeletal muscle. (a) Amounts of FAT/CD36, SCD1, ACO, and UCP2 in skeletal muscles (a) of KKAy mice. (b-d) FA-CoA (b) and TG (c) content and expression and insulin-induced tyrosine phosphorylation of IR, IRS-1 and -2, and insulin-stimulated PI 3-kinase activity (d) in skeletal muscles of KKAy mice, untreated (HF) or treated with HX531 (HF + HX531) or with BADGE (HF + BADGE) for 2 weeks while on the HF diet. ( $b$ and $\mathbf{c}$ ) Tissue homogenates were extracted, and their TG and FA-CoA content was determined as described previously $(22,26)$, with some modifications. (d) Mice were stimulated with or without $1 \mathrm{Ug}^{-1}$ body weight of insulin for 2 minutes. Lysates were immunoprecipitated (IP) with the Ab's indicated, followed by immunoblotting with the Ab's indicated or kinase assay for PI. Labeled PI (PIP) was subjected to thin-layer chromatography and autoradiography as described previously (21). HX531 or BADGE was given as a $0.1 \%$ or $3 \%$ food admixture, respectively. Each bar represents the mean $\pm \mathrm{SE}(n=5-10) .{ }^{*} P<0.05,{ }^{*} P<0.01, \mathrm{HF}$ versus HF $+\mathrm{HX} 531$ or HF + BADGE. 
a

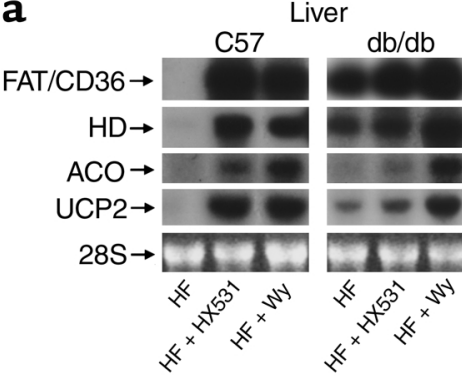

b

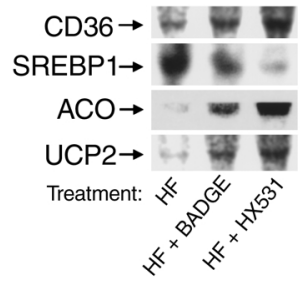

C
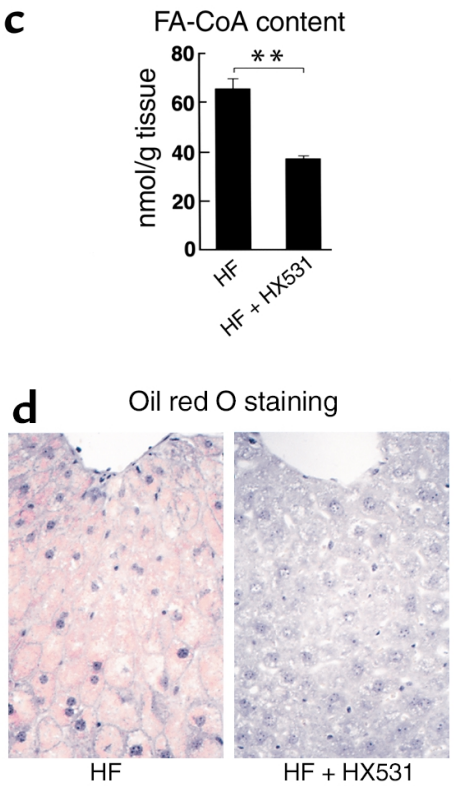

e

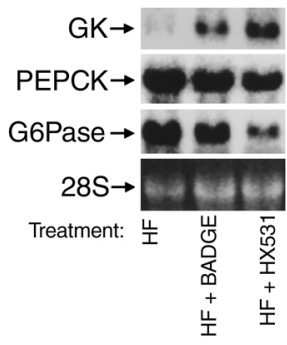

f
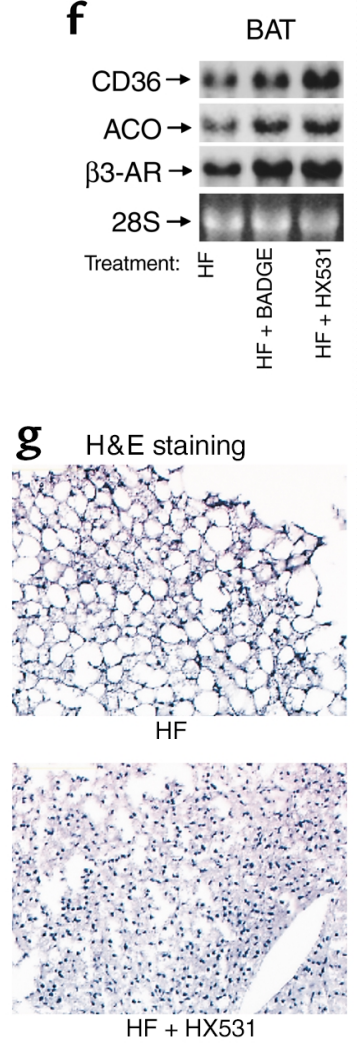

Figure 6

The RXR antagonist HX531 and the PPAR $\gamma$ antagonist BADGE both increase molecules involved in fatty acid combustion and energy dissipation via leptin and PPAR $\alpha$ pathways in the liver and BAT $(\mathbf{a}, \mathbf{b}, \mathbf{e}, \mathbf{f})$. Amounts of the mRNAs of FAT/CD36, SREBP1, HD (peroxisomal enoyl-CoA hydratase/3-hydroxyacyl-CoA dehydrogenase), ACO, $U C P 2$, and $\beta 3$-AR in livers from $C 57$ and $d b / d b$ mice (a), in livers from KKAy mice (b), in BAT from KKAy mice (f), and glucokinase, PEPCK, and G6Pase in livers from KKAy mice $(\mathbf{e})$. (c, d, g) Hepatic FA-CoA content (c), hepatic TG content (oil red O staining) (d), size of brown adipocytes from KKAy mice (g), untreated (HF) or treated with HX531 $(\mathrm{HF}+\mathrm{HX531}), \mathrm{Wy}-14,643(\mathrm{HF}+\mathrm{Wy})$, or BADGE $(\mathrm{HF}+\mathrm{BADGE})$ for 2 weeks while on the HF diet. HX531, or Wy-14,643, or BADGE was given as a $0.1 \%, 0.01 \%$, or $3 \%$ food admixture, respectively. Each bar represents the mean $\pm \mathrm{SE}(n=5-10) .{ }^{*} P<0.05, * * P<0.01$, HF versus $\mathrm{HF}+\mathrm{HX} 531$ or $\mathrm{HF}+\mathrm{BADGE}$.

phosphatase (G6Pase) (Figure 6e), and increased glycogen content (34) (data not shown), indicating increased insulin actions in the liver (43).

In brown adipose tissue (BAT), where PPAR $\alpha$ was relatively abundantly expressed as compared with WAT,

expression of FAT/CD36 was increased by treatment with the RXR antagonist HX531 (Figure 6f) in contrast to WAT (Figure 4a). HX531 or BADGE also increased expression of ACO, which is primarily involved in the regulation of $\beta$-oxidation in BAT, and $\beta 3$-AR (Figure $6 \mathrm{f}$. . The increased expressions of $\mathrm{CD} 36$ and $\mathrm{ACO}$ by the RXR antagonist or the PPAR $\gamma$ antagonist appeared to be caused by activation of PPAR $\alpha$ pathways $(19,22,42)$, similar to those in the liver. On the other hand, the increased expression of $\beta 3$-AR appeared to be a direct effect of increased leptin signaling (Figure $3 c$ and Figure 7c) (38) and decreased PPAR $\gamma /$ RXR effects (Figure $1 \mathrm{~b}$ and Figure 4a) (39). Increases in the expression of these molecules in concert may provide the mechanism whereby BAT mass and brown adipocyte hypertrophy were reduced (Figure 6g) in mice treated with HX531 or BADGE while on the HF diet. This is consistent with increased energy expenditure and protection against adipocyte hypertrophy by RXR antagonist or PPAR $\gamma$ antagonist treatment.

Treatment of heterozygous PPAR $\gamma$-deficient mice with an $R X R$ antagonist or a PPAR $\gamma$ antagonist results in re-emergence of hyperglycemia and insulin resistance associated with lipoatrophy. To investigate the effects of the RXR antagonist or the PPAR $\gamma$ antagonist on mice with moderately reduced PPAR $\gamma$ activity, we studied the phenotypes of HX531- or BADGE-treated heterozygous PPAR $\gamma$-deficient mice as compared with those of untreated wild-type, HX531-, or BADGE-treated wild-type mice on the HF diet. Moderately reduced expression of CD36 in WAT was observed in wild-type mice treated with BADGE or HX531 ( 40 or $70 \%$, respectively) (Figure 7a, lanes 2 and 3 ), suggesting the possibility that PPAR $\gamma / \mathrm{RXR}$ activity may be moderately decreased in wild-type mice treated with BADGE or HX531. Treatment of heterozygous PPAR $\gamma$-deficient mice with BADGE or HX531 resulted in further decreased expression of CD36 in WAT (Figure 7a, lanes 4 and 5), raising the possibility that PPAR $\gamma /$ RXR activity may be severely decreased in heterozygous PPAR $\gamma$-deficient mice treated with BADGE or HX531. Wild-type mice treated with BADGE or HX531 were protected from HF diet-induced increases in WAT mass (Figure $7 \mathrm{~b}$, lanes 2 and 3). Administration of BADGE or HX531 to heterozygous PPAR $\gamma$-deficient mice for 4 weeks resulted in disappearance of visible WAT, i.e., lipoatrophy (Figure $7 b$, lanes 5 and 6$)(25,44,45)$.

Wild-type mice treated with BADGE or HX531 showed higher serum leptin levels than untreated wildtype mice on the HF diet (Figure 7c, lanes 1-3), presumably due to decreased PPAR $\gamma /$ RXR-mediated suppression of leptin gene transcription (36). The serum leptin levels of heterozygous PPAR $\gamma$-deficient mice treated with BADGE or HX531 were, however, markedly reduced (Figure $7 c$, lanes 5 and 6 ) as a result of WAT depletion (Figure 7b, lanes 5 and 6) $(19,44)$.

Wild-type mice treated with BADGE or HX531 were protected from HF diet-induced hyperglycemia and insulin resistance (Figure 7d, lanes 2 and 3). Paradoxically, treatment of heterozygous PPAR $\gamma$-deficient mice 
with BADGE or HX531 resulted in a re-emergence of hyperglycemia and insulin resistance (Figure $7 \mathrm{~d}$, lanes 5 and 6$)(25,44,45,46)$, as compared with wild-type mice treated with BADGE or HX531 on the HF diet.

The combination of leptin deficiency and decreased effects of PPAR $\alpha$ pathways leads to insulin resistance in heterozygous PPAR $\gamma$-deficient mice without WAT induced by treatment with an RXR antagonist or a PPAR $\gamma$ antagonist. BADGE- or HX531-treated wild-type mice exhibited decreased hepatic expression of lipogenic enzymes such as SREBP1 (data not shown) and SCD1 (Figure 8a, lanes 2 and 3 ) by increased serum leptin levels (Figure 7c, lanes 2 and 3). Moreover, these mice showed increased expression of $\mathrm{UCP} 2$ and enzymes involved in $\beta$-oxidation (Figure 8a, lanes 2 and 3), presumably by increased activation of PPAR $\alpha$ pathways (Figure 6a). In marked contrast, induction of SREBP1 (data not shown) and SCD1 (Figure 8a, lanes 5 and 6) due to markedly decreased serum leptin levels (Figures $7 c$, lanes 5 and 6$)(38,42)$ and decreased effects of PPAR $\alpha$ pathways, such as reduced expressions of ACO and UCP2 (Figure 8a, lanes 4 and 5, and data not shown) $(18,19,22,31)$, were observed in heterozygous PPAR $\gamma$-deficient mice treated with BADGE or HX531. These alterations of gene expression in concert appeared to increase tissue TG content in heterozygous PPAR $\gamma$ deficient mice treated with BADGE or HX531 (Figure $8 \mathrm{~b}$, lanes 5 and 6 ), in contrast to the decreased tissue TG content seen in wild-type mice treated with BADGE or HX531 (Figure 8b, lanes 2 and 3).

Similarly, in skeletal muscle, treatment of heterozygous PPAR $\gamma$-deficient mice with BADGE or HX531 increased expressions of SREBP1 (Figure $8 c$, lanes 5 and 6) and SCD1 (data not shown), decreased expressions of $\mathrm{ACO}$ and UCP2 (Figure 8c, lanes 5 and 6) and concomitantly increased the tissue TG content (Figure 8d, lanes 5 and 6) as compared with treatment of wild-type mice with BADGE or HX531 (Figure 8, c and d, lanes 2 and 3).

To determine the relative contributions of leptin deficiency and decreased effects of PPAR $\alpha$ pathways to the insulin resistance observed in heterozygous PPAR $\gamma$-deficient

\section{Figure 7}

Treatment of heterozygous PPAR $\gamma$-deficient mice with an RXR antagonist or PPAR $\gamma$ antagonist results in reemergence of hyperglycemia and insulin resistance associated with lipoatrophy. (a) Amounts of the mRNAs of FAT/CD36 in WAT. (b-d) WAT mass (b), serum leptin levels (c), insulin resistance index (d), of wild-type (WT) and heterozygous PPAR $\gamma$-deficient mice $(+/-)$ untreated (-) or treated with HX531 or BADGE for 3 weeks (a) or for 4 weeks (b-d) while on the HF diet. HX531 or BADGE was given as a $0.1 \%$ or $3 \%$ food admixture, respectively. Each bar represents the mean $\pm \mathrm{SE}$ $(n=5-10) .{ }^{*} P<0.05,{ }^{*} P<0.01$, untreated versus treated with HX531 or BADGE or compared with untreated wild-type mice. NS, no significant difference. mice without WAT induced by treatment with HX531or BADGE, we supplied the mice with leptin and/or Wy14,643 , a PPAR $\alpha$ agonist. Very low plasma leptin levels were restored to almost the control value by continuous systemic infusion of a low dose of recombinant leptin (Figure 8e, left, lanes 2 and 3 ), which partially alleviated insulin resistance (Figure 8e, right, lanes 2 and 3). We found that $\mathrm{Wy}-14,643$ treatment also partially reversed the insulin resistance seen in HX531- or BADGE-treated heterozygous PPAR $\gamma$-deficient mice (Figure 8e, right, lanes 2 and 5). Interestingly, combining physiological doses of leptin and Wy-14,643 almost completely ameliorated insulin resistance (Figure 8e, right, lanes 2 and 6), presumably due to reduced tissue TG content (data not shown). These data suggested that leptin deficiency and decreased effects of PPAR $\alpha$ pathways caused insulin resistance by different mechanisms, at least to some extent. However, the insulin resistance in these mice could be completely overcome by continuous infusion of a high dose of leptin (Figure 8e, right, lanes 2 and 4). Interestingly, we very recently found that in combination with leptin, physiological dose of adiponectin ameliorated insulin resistance observed in our lipotrophic mice presumably through activation of PPAR $\gamma$ pathways (47).

\section{Discussion}

Effect of the RXR antagonist HX531 and the PPAR $\gamma$ antagonist $B A D G E$ on the regulation of insulin sensitivity. This study demonstrated that treatment of wild-type mice with the RXR antagonist HX531 or the PPAR $\gamma$ antago-

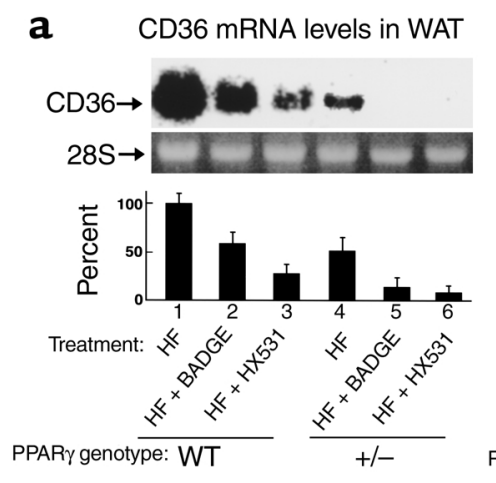

b
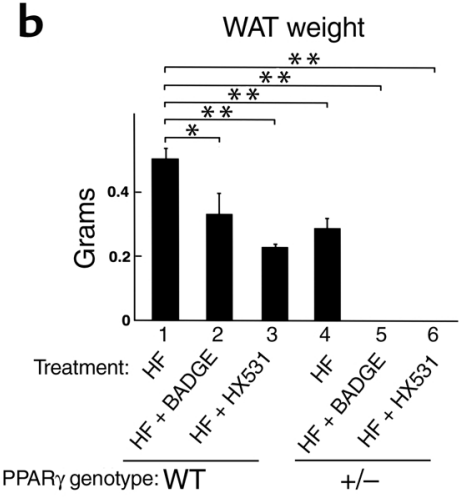

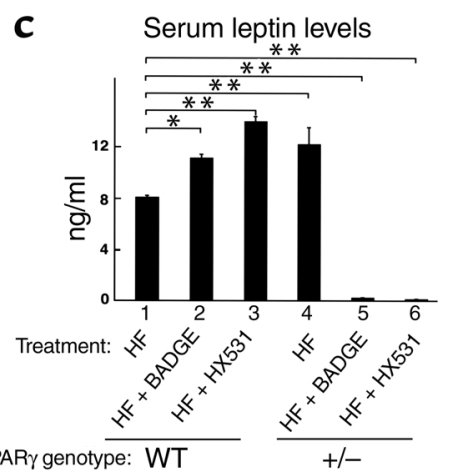

d
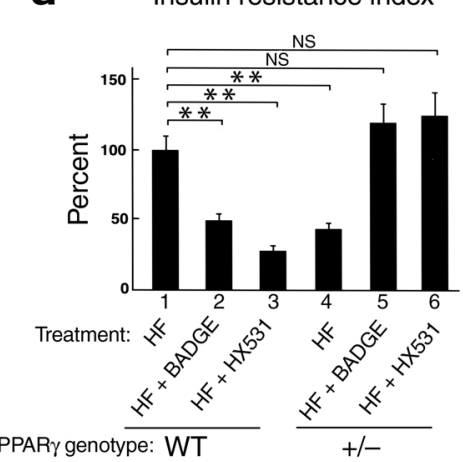
a

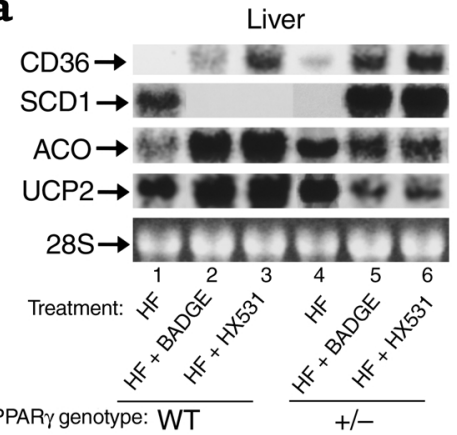

b
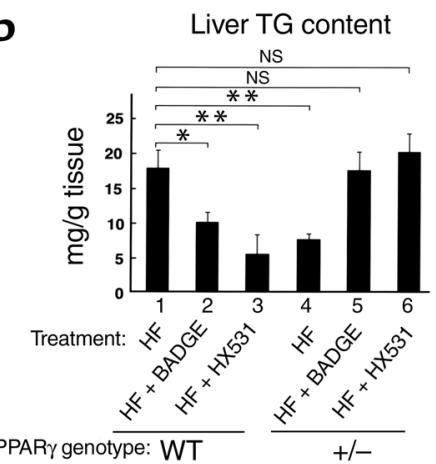

C

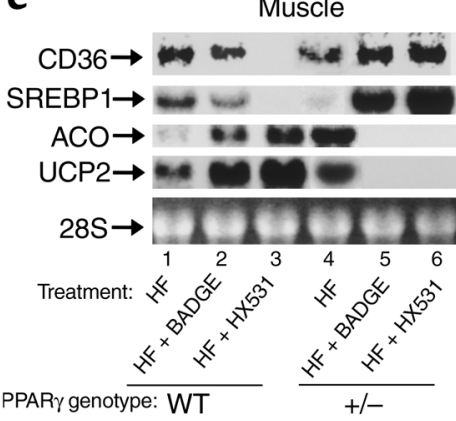

d
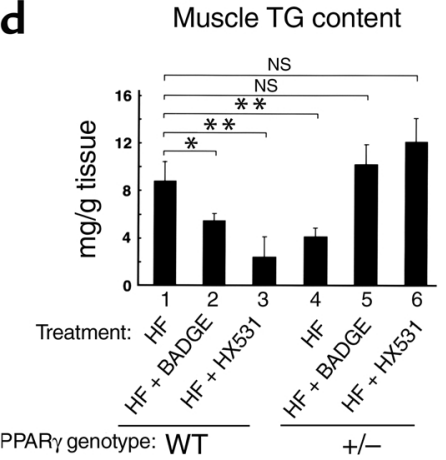

e

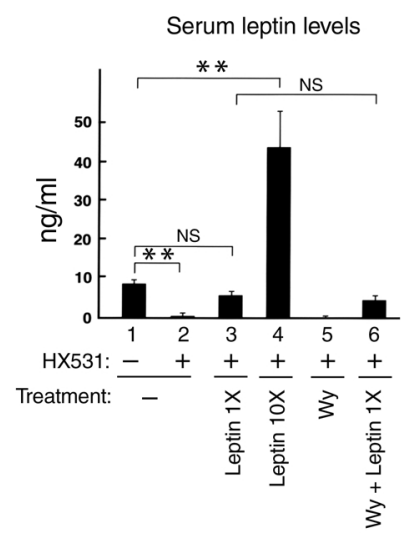

PPAR $\gamma^{+-}$

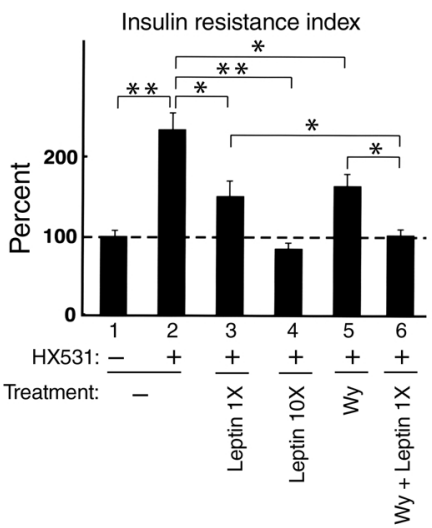

\section{Figure 8}

The combination of leptin deficiency and decreased effects of PPAR $\alpha$ pathways results in insulin resistance in heterozygous PPAR $\gamma$-deficient mice without WAT induced by treatment with an RXR antagonist or a PPAR $\gamma$ antagonist ( $\mathbf{a}$ and $\mathbf{c}$ ). Amounts of the mRNAs of FAT/CD36, SREBP1, SCD1, ACO, and UCP2 in the liver (a) and in skeletal muscle (c). (b and d) TG content of the livers (b) and skeletal muscles (d) of wild-type (WT) and heterozygous PPAR $\gamma$-deficient mice $(+/-)$ untreated (-) or treated with HX531 or BADGE for 4 weeks (a-d) while on the HF diet. (e) Serum leptin levels (left) and insulin resistance index (right) of heterozygous PPAR $\gamma$-deficient mice (PPAR $\left.\gamma^{+/}\right)$untreated $(-)$or treated with HX531 (+) for 6 weeks or PPAR $\gamma^{+/-}$treated with low doses of leptin (Lep1X), high doses of leptin (Lep10X), Wy-14,643 (Wy), or a combination for the last 12 days of a 6-week HX531 treatment while on the HF diet. HX531 or Wy-14,643 was given as a 0.1 or $0.01 \%$ food admixture, respectively. The results are expressed as the percentage of the value of untreated PPAR $\gamma^{+/-}$on the HF diet (right). HX531 or Wy-14,643 was given as a 0.1 or $0.01 \%$ food admixture, respectively. Each bar represents the mean $\pm \mathrm{SE}(n=5-10) .{ }^{*} P<0.05,{ }^{*} P<0.01$, untreated versus treated with HX531, Lep1X, Lep10X, or Wy, or compared with untreated wildtype mice. NS, no significant difference.

nist BADGE prevented HF diet-induced obesity, insulin resistance, and diabetes by reducing tissue TG content in WAT, skeletal muscle, and the liver by at least three mechanisms. First, the RXR antagonist HX531 and the PPAR $\gamma$ antagonist BADGE reduced expression of PPAR $\gamma$ target genes such as CD36 in tissues where PPAR $\gamma$ was expressed predominantly (Figure $4 \mathrm{a}$ and $5 \mathrm{a}$ ), which could limit fatty acid influx into WAT and skeletal muscle $(19,37)$. Second, the RXR antagonist and the PPAR $\gamma$ antagonist increased serum leptin levels and leptin sensitivity (Figure 3, c, d, f and $7 c$ ) and indeed increased its effects, i.e., reduced lipogenic enzymes and induction of $\beta 3$-AR (Figures $4 \mathrm{a}, 5 \mathrm{a}, 6 \mathrm{~b}$ and $6 \mathrm{f}$ ) (38), as genetically demonstrated by the significant attenuation of their antiobesity and antidiabetic effects in leptin receptor-deficient mice (Figure 3, g and $\mathrm{h}$ ). In KKAy mice, however, it is difficult to judge whether increased leptin effects could play a predominant role in driving the decreased weight gain and metabolic effects resulting from HX531 treatment, raising the alternative possibility that in KKAy mice leptin-independent pathways may play more role in these effects. Third, HX531 and BADGE increased expression of PPAR $\alpha$ target genes such as ACO and UCP2 (Figures $5 \mathrm{a}$ and Figure 6, a, b, and $\mathrm{f}$ ) in tissues in which PPAR $\alpha$ was expressed, thereby increasing fatty acid combustion and energy dissipation in the liver, BAT, and skeletal muscle; these observations fit well with recently demonstrated effects of PPAR $\alpha$ agonists on insulin resistance (48) and decreased fatty acid combustion in PPAR $\alpha$ deficient mice (49).

All three effects, downregulation of molecules involved in TG accumulation and activation of leptin and PPAR $\alpha$ pathways, appear probably to be consequences of moderate reduction of PPAR $\gamma /$ RXR activity for the following two reasons. First, the RXR antagonist HX531 and the PPAR $\gamma$ antagonist BADGE exerted these three effects essentially in proportion to their potencies as PPAR $\gamma /$ RXR inhibitors in vitro. Second, with respect to these three effects, untreated heterozygous PPAR $\gamma$-deficient mice exhibited the same molecular pathophysiology as wild-type mice treated with HX531 or BADGE (Figures 7 and 8). Very recently, mice lacking RXR $\alpha$ in adipocytes have also been reported to be resistant to HF diet-induced obesity (50). Although the authors speculated that RXR $\alpha$ mediated this effect as a heterodimeric partner for 
PPAR $\gamma$, the possibility could not be excluded that HX531 may mediate some of the effects that were observed in this study, particularly in vivo, by acting on other heterodimeric partners for RXR. Previously, HX531 was reported to be an antagonist of RXR homodimers and of the RAR/RXR heterodimer on the basis of inhibitory activity on transactivation assay in COS-1 cells (17). Although it had minimal effects on the numbers of peripheral blood leukocytes and bone marrow blasts in vivo, interaction with these receptor dimers may account for the present findings to some extent. Thus, the relative contributions of PPAR $\gamma, \mathrm{RXR}$, and/or their cognate endogenous ligands, as well as the potential contributions of other heterodimeric partners for RXR in mediating all the effects of HX531 or BADGE, will require further study.

On the basis of our data, we would like to propose the following possible hypothesis that may explain the mechanisms by which PPAR $\gamma / \mathrm{RXR}$ regulates insulin sensitivity. On the HF diet, "normal" amounts of PPAR $\gamma /$ RXR activity seen in wild-type mice increases TG content in WAT, skeletal muscle, and the liver due to a combination of increased fatty acid influx into these tissues and HF diet-induced leptin resistance, leading to insulin resistance associated with obesity. By contrast, the moderate reduction of PPAR $\gamma / \mathrm{RXR}$ activity observed in HX531- or BADGE-treated wildtype mice decreases the TG content in WAT, skeletal muscle, and the liver due to a combination of direct antagonism of PPAR $\gamma /$ RXR to limit fatty acid influx into WAT and skeletal muscle and increased leptin expression by antagonism of PPAR $\gamma /$ RXR-mediated suppression of the gene, thereby reducing expression of lipogenic enzymes. Moreover, consequent activation of the PPAR $\alpha$ pathway in the liver, BAT, and skeletal muscle, increases expression of UCP2 and enzymes involved in $\beta$-oxidation. These alterations lead to prevention of HF diet-induced obesity and insulin resistance. Severely reducing PPAR $\gamma /$ RXR activity, however, depletes WAT in part due to severely decreased flux of FFA into WAT by marked suppression of target genes of PPAR $\gamma /$ RXR, leading to increased FA influx into liver/muscle and simultaneously to both leptin deficiency and decreased effects of PPAR $\alpha$ pathways. These alterations lead to increased expression of lipogenic enzymes and decreased expression of enzymes involved in $\beta$-oxidation and UCP2, thereby markedly increasing skeletal muscle and liver tissue TG content, which can account for the re-emergence of insulin resistance in the face of lipoatrophy. The results obtained in this study may collectively raise the possibility that PPAR $\gamma /$ RXR regulates fuel partitioning among tissues, the net effects of leptin and PPAR $\alpha$ activity, thereby playing an important role in the regulation of insulin sensitivity.

The appropriate level of PPAR $\gamma / R X R$ activity for insulin sensitivity. There may be an appropriate level of PPAR $\gamma /$ RXR activity for insulin sensitivity. Taken together, our data raise the possibility that there may be a hitherto unrecognized U-shaped relationship between PPAR $\gamma /$ RXR activity and insulin resistance within physiologically "normal" limits (Figure 9). The relationship between PPAR $\gamma /$ RXR activity and WAT mass may be linear. There may be an appropriate level of PPAR $\gamma /$ RXR activity for insulin sensitivity, which may be approximately $30-60 \%$ of "normal." Increases in PPAR $\gamma /$ RXR activity are associated with decreased serum leptin levels due to increased PPAR $\gamma /$ RXR-mediated suppression of leptin gene transcription, and decreases in PPAR $\gamma /$ RXR activity may be associated with decreased serum leptin levels due to WAT depletion. Thus, the relationship between PPAR $\gamma /$ RXR activity and leptin appears to exhibit an inverted U-shaped curve. Thus, impairment of the leptin pathway may be closely paralleled by impairment of insulin sensitivity.

HF diet-induced obesity is the major risk factor for diabetes and cardiovascular diseases, the prevalences of which are increasing dramatically. Although genetic evidence has strongly suggested PPAR $\gamma$ to act as a thrifty gene $(5,11)$, the molecular mechanisms accounting for this function of the gene were unclear $(2,51)$. We have shown herein that PPAR $\gamma /$ RXR promotes fat storage in the body by a combination of direct induction of molecules involved in TG accumulation and suppression of leptin gene expression as well as inactivation of PPAR $\alpha$-signaling pathways. In times of fasting, this PPAR $\gamma /$ leptin/PPAR $\alpha$ network maximizes energy storage, which is quite advantageous for survival. In times of feast, which are the norm in industrialized nations nowadays, however, this network caus-

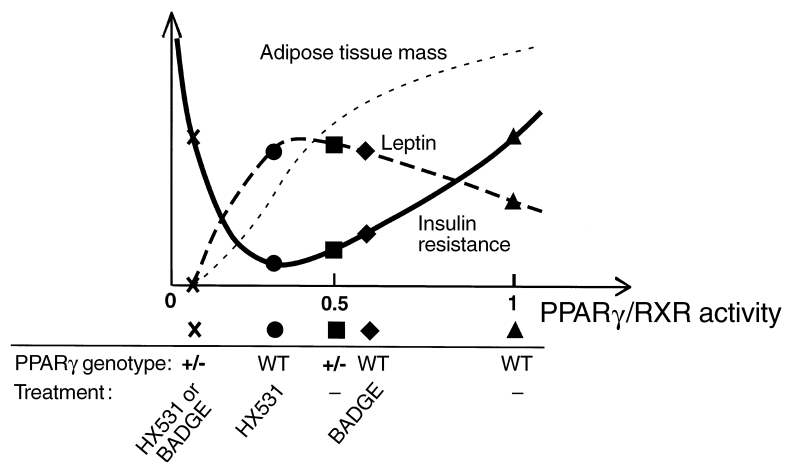

Figure 9

One possible model for the relationship between PPAR $\gamma /$ RXR activity and insulin sensitivity on the HF diet. The relationship between PPAR $\gamma /$ RXR activity and WAT mass may be linear. There may appear to be an optimal level of PPAR $\gamma /$ RXR activity for insulin sensitivity that is approximately 0.3-0.5 times normal. Increases in PPAR $\gamma / R X R$ activity as compared with the optimal range are associated with decreased serum leptin levels due to increased PPAR $\gamma /$ RXR-mediated suppression of leptin gene transcription, and decreases in PPAR $\gamma / R X R$ activity may be associated with decreased serum leptin levels due to depletion of WAT. Thus, these data raise the possibility that the relationship between PPAR $\gamma / R X R$ activity and leptin is an inverted $U$-shaped curve. The relationship between PPAR $\gamma / R X R$ activity and insulin resistance appears to exhibit such a U-shaped curve. Thus, impairment of the leptin pathway may closely parallel impairment of insulin sensitivity. 
es excessive adiposity, insulin resistance, and obesityrelated diseases such as diabetes. Thus appropriate antagonism of PPAR $\gamma / \mathrm{RXR}$, which simultaneously leads to appropriate agonism of leptin and PPAR $\alpha$, may be a logical approach to protection against obesity and related diseases such as type 2 diabetes. In this respect, treating subjects with the wild-type PPAR $\gamma$ (Pro 12 allele) with higher activity with PPAR $\gamma / \mathrm{RXR}$ inhibitors is an example for "personalized treatment" of subjects genetically susceptible to obesity and diabetes. In contrast, our data raise the possibility that treating subjects with the variant PPAR $\gamma$ (Ala 12 allele) with lower PPAR $\gamma$ activity with PPAR $\gamma /$ RXR inhibitors may worsen their insulin resistance (46).

Although not shown in this study, we have also found that supraphysiological activation of PPAR $\gamma$, far beyond 1 (PPAR $\gamma$ activity in wild-type mice on the HF diet), by TZD induces adipocyte differentiation, thereby increasing the number of small adipocytes (8). This in turn promotes a flux of FFA from the liver and muscle into WAT, leading to decreased liver and muscle TG content and improvement of insulin sensitivity at the expense of increased WAT mass, i.e., obesity (52). However, PPAR $\gamma$ activators including TZD have been reported to prevent atherosclerosis by reducing lipid accumulation in foamy arterial macrophages and also to inhibit cytokine production and inflammation, raising the possibility that PPAR $\gamma$ inhibitors promote atherosclerosis (53-55). Thus, like tissue-specific agonist/antagonist for the estrogen receptor tamoxifen, a tissue-specific PPAR $\gamma$ agonist/antagonist that functions as an agonist in arterial macrophages and simultaneously antagonizes PPAR $\gamma$ in adipose tissue may be the ultimate drug for treating obesity, type 2 diabetes, and atherosclerosis.

\section{Acknowledgments}

We thank T. Hashimoto for the generous gift of a DNA probe for ACO. We are grateful to T. Takahashi, Y. Tanaka, S. Uchida, K. Kirii, M. Kamon, S. Sakata, and T. Nagano for their excellent technical assistance. This work was supported by a grant from the Research Fellowships of the Japan Society for the Promotion of Science for Young Scientists (to T. Yamauchi), a Grant-inAid for the Development of Innovative Technology from the Ministry of Education, Culture, Sports, Science and Technology (to T. Kadowaki), a Grant-in Aid for Creative Scientific Research 10NP0201 from Japan Society for the Promotion of Science (to T. Kadowaki), and by Health Science Research Grants (Research on Human Genome and Gene Therapy) from the Ministry of Health and Welfare (to T. Kadowaki).

1. Kersten, S., Desvergne, B., and Wahli, W. 2000. Roles of PPARs in health and disease. Nature. 405:421-424.

2. Lowell, B.B. 1999. PPARgamma: an essential regulator of adipogenesis and modulator of fat cell function. Cell. 99:239-242.

3. Spiegelman, B.M., and Flier, J.S. 1996. Adipogenesis and obesity: rounding out the big picture. Cell. 87:377-389.

4. Gonzalez, F.J. 1997. Recent update on the PPAR alpha-null mouse. Biochimie. 79:139-144.

5. Auwerx, J. 1999. PPARgamma, the ultimate thrifty gene. Diabetologia. 42:1033-1049.
6. Lehmann, J.M., et al. 1995. An antidiabetic thiazolidinedione is a high affinity ligand for peroxisome proliferator-activated receptor $\gamma$. J. Biol. Chem. 270:12953-12956.

7. Mukherjee, R., et al. 1997. Sensitization of diabetic and obese mice to insulin by retinoid $X$ receptor agonists. Nature. 386:407-410.

8. Okuno, A., et al. 1998. Troglitazone increases the number of small adipocytes without the change of white adipose tissue mass in obese Zucker rats. J. Clin. Invest. 101:1354-1361.

9. Malinowski, J.M., and Bolesta, S. 2000. Rosiglitazone in the treatment of type 2 diabetes mellitus: a critical review. Clin. Ther. 22:1151-1168.

10. UK Prospective Diabetes Study (UKPDS) Group. 1998. Effect of intensive blood-glucose control with metformin on complications in overweight patients with type 2 diabetes (UKPDS 34). Lancet. 352:854-865.

11. Kubota, N., et al. 1999. PPAR gamma mediates high-fat diet-induced adipocyte hypertrophy and insulin resistance. Mol. Cell. 4:597-609.

12. Miles, P.D., Barak, Y., He, W., Evans, R.M., and Olefsky, J.M. 2000. Improved insulin-sensitivity in mice heterozygous for PPAR-gamma deficiency. J. Clin. Invest. 105:287-292.

13. Deeb, S.S., et al. 1998. A Pro12Ala substitution in PPARgamma2 associated with decreased receptor activity, lower body mass index and improved insulin sensitivity. Nat. Genet. 3:284-287.

14. Hara, K., et al. 2000. The Pro12Ala polymorphism in PPAR gamma2 may confer resistance to type 2 diabetes. Biochem. Biophys. Res. Commun. 271:212-216.

15. Altshuler, D., et al. 2000. The common PPARgamma Pro12Ala polymorphism is associated with decreased risk of type 2 diabetes. Nat. Genet. 26:76-80.

16. Wright, H.M., et al. 2000. A synthetic antagonist for the peroxisome proliferator-activated receptor gamma inhibits adipocyte differentiation. J. Biol. Chem. 275:1873-1877.

17. Ebisawa, M., et al. 1999. Retinoid X receptor-antagonistic diazepinylbenzoic acids. Chem. Pharm. Bull. (Tokyo). 47:1778-1786.

18. Tsuboyama-Kasaoka, N., Takahashi, M., Kim, H., and Ezaki, O. 1999. Upregulation of liver uncoupling protein-2 mRNA by either fish oil feeding or fibrate administration in mice. Biochem. Biophys. Res. Commun. 257:879-885.

19. Motojima, K., Passilly, P., Peters, J.M., Gonzalez, F.J., and Latruffe, N. 1998. Expression of putative fatty acid transporter genes are regulated by peroxisome proliferator-activated receptor alpha and gamma activators in a tissue- and inducer-specific manner. J. Biol. Chem. 273:16710-16714.

20. Vidal-Puig, A., et al. 1996. Regulation of PPAR gamma gene expression by nutrition and obesity in rodents. J. Clin. Invest. 97:2553-2561.

21. Yamauchi, T., et al. 1996. Insulin signalling and insulin actions in the muscles and livers of insulin-resistant, insulin receptor substrate 1-deficient mice. Mol. Cell. Biol. 16:3074-3084.

22. Murakami, K., et al. 1998. A novel insulin sensitizer acts as a coligand for peroxisome proliferator-activated receptor-alpha (PPAR-alpha) and PPAR-gamma: effect of PPAR-alpha activation on abnormal lipid metabolism in liver of Zucker fatty rats. Diabetes. 47:1841-1847.

23. Yanagisawa, J., et al. 1999. Convergence of transforming growth factorbeta and vitamin $\mathrm{D}$ signaling pathways on SMAD transcriptional coactivators. Science. 283:1317-1321.

24. Kliewer, S.A., et al. 1994. Differential expression and activation of a family of murine peroxisome proliferator-activated receptors. Proc. Natl. Acad. Sci. USA. 91:7355-7359.

25. Shimomura, I., Hammer, R.E., Ikemoto, S., Brown, M.S., and Goldstein, J.L. 1999. Leptin reverses insulin resistance and diabetes mellitus in mice with congenital lipodystrophy. Nature. 401:73-76.

26. Mangino, M.J., Zografakis, J., Murphy, M.K., and Anderson, C.B. 1992. Improved and simplified tissue extraction method for quantitating longchain acyl-coenzyme A thioesters with picomolar detection using highperformance liquid chromatography. J. Chromatogr. 577:157-162.

27. Forman, B.M., et al. 1995. 15-Deoxy-delta 12, 14-prostaglandin J2 is a ligand for the adipocyte determination factor PPAR gamma. Cell. 83:813-819.

28. Kliewer, S.A., et al. 1995. A prostaglandin J2 metabolite binds peroxisome proliferator-activated receptor gamma and promotes adipocyte differentiation. Cell. 83:803-812.

29. Heyman, R.A., et al. 1992. 9-cis retinoic acid is a high affinity ligand for the retinoid X receptor. Cell. 68:397-406.

30. Levin, A.A., et al. 1992. 9-cis retinoic acid stereoisomer binds and activates the nuclear receptor RXR alpha. Nature. 355:359-361.

31. Kelly, L.J., et al. 1998. Peroxisome proliferator-activated receptors gamma and alpha mediate in vivo regulation of uncoupling protein (UCP-1, UCP-2, UCP-3) gene expression. Endocrinology. 139:4920-4927.

32. Forman, B.M., Chen, J., and Evans, R.M. 1997. Hypolipidemic drugs, polyunsaturated fatty acids, and eicosanoids are ligands for peroxisome proliferator-activated receptors alpha and delta. Proc. Natl. Acad. Sci. USA. 94:4312-4317.

33. Mark, M., et al. 1999. A genetic dissection of the retinoid signalling pathway in the mouse. Proc. Nutr. Soc. 58:609-613.

34. Masuzaki, H., et al. 1999. Glucose metabolism and insulin sensitivity in 
transgenic mice overexpressing leptin with lethal yellow agouti mutation: usefulness of leptin for the treatment of obesity-associated diabetes. Diabetes. 48:1615-1622.

35. Friedman, J.M. 2000. Obesity in the new millennium. Nature. 404:632-634.

36. Hollenberg, A.N., et al. 1997. Functional antagonism between CCAAT/Enhancer binding protein-alpha and peroxisome proliferator-activated receptor-gamma on the leptin promoter. J. Biol. Chem. 272:5283-5290.

37. Tontonoz, P., Nagy, L., Alvarez, J.G., Thomazy, V.A., and Evans, R.M. 1998 PPARgamma promotes monocyte/macrophage differentiation and uptake of oxidized LDL. Cell. 93:241-252.

38. Soukas, A., Cohen, P., Socci, N.D., and Friedman, J.M. 2000. Leptin-specific patterns of gene expression in white adipose tissue. Genes Dev. 14:963-980.

39. Bakopanos, E., and Silva, J.E. 2000. Thiazolidinediones inhibit the expression of beta3-adrenergic receptors at a transcriptional level. Diabetes. 49:2108-2115.

40. Hotamisligil, G.S. 1999. The role of TNFalpha and TNF receptors in obesity and insulin resistance. J. Intern. Med. 245:621-625.

41. Steppan, C.M., et al. 2001. The hormone resistin links obesity to diabetes. Nature. 409:307-312.

42. Unger, R.H., Zhou, Y.T., and Orci.L. 1999. Regulation of fatty acid homeostasis in cells: novel role of leptin. Proc. Natl. Acad. Sci. USA. 96:2327-2332.

43. Shulman, G.I. 2000. Cellular mechanisms of insulin resistance. J. Clin. Invest. 106:171-176.

44. Moitra, J., et al. 1998. Life without white fat: a transgenic mouse. Genes Dev. 12:3168-3181

45. Seip, M., and Trygstad, O. 1996. Generalized lipodystrophy, congenital and acquired (lipoatrophy). Acta Paediatr. Suppl. 413:2-28.

46. Barroso, I., et al. 1999. Dominant negative mutations in human PPARgamma associated with severe insulin resistance, diabetes mellitus and hypertension. Nature. 402:880-883.

47. Yamauchi, T., et al. 2001. The fat-derived hormone adiponectin reverses insulin resistance associated with both lipoatrophy and obesity.

48. Guerre-Millo, M., et al. 2000. Peroxisome proliferator-activated receptor alpha activators improve insulin sensitivity and reduce adiposity. J. Biol. Chem. 275:16638-16642.

49. Kersten, S., et al. 1999. Peroxisome proliferator-activated receptor alpha mediates the adaptive response to fasting. J. Clin. Invest. 103:1489-1498.

50. Imai, T., Jiang, M., Chambon, P., and Metzger, D. 2001. Impaired adipogenesis and lipolysis in the mouse upon selective ablation of the retinoid $\mathrm{X}$ receptor $\alpha$ mediated by a tamoxifen-inducible chimeric Cre recombinase (Cre-ERT2) in adipocytes. Proc. Natl. Acad. Sci. USA. 98:224-228.

51. Kahn, R.C., Chen, L., and Cohen, S.E. 2000. Unraveling the mechanism of action of thiazolidinediones. J. Clin. Invest. 106:1305-1307.

52.Yamauchi, T., et al. 2001. The mechanisms by which both heterozygous $\operatorname{PPAR} \gamma$ deficiency and PPAR $\gamma$ agonist improve insulin resistance. J. Biol. Chem. In press.

53. Moore, K.J., et al. 2001. The role of PPAR-gamma in macrophage differentiation and cholesterol uptake. Nat. Med. 7:41-47.

54. Chawla, A., et al. 2001. PPAR-gamma dependent and independent effects on macrophage-gene expression in lipid metabolism and inflammation. Nat. Med. 7:48-52.

55. Chinetti, G., et al. 2001. PPAR-alpha and PPAR-gamma activators induce cholesterol removal from human macrophage foam cells through stimulation of the ABCA1 pathway. Nat. Med. 7:53-58. 